\title{
Prevention of thermal and condensation errors in pneumotachographic recordings of the maximal forced expiratory manoeuvre
}

\author{
M.R. Miller*, T. Sigsgaard**
}

Prevention of thermal and condensation errors in pneumotachographic recordings of the maximal forced expiratory manoeuvre. M.R. Miller, T. Sigsgaard. CERS Journals Ltd 1994.

ABSTRACT: When recording respiratory manoeuvres using a pneumotachograph (PT), it is customary to heat the pneumotachograph head to avoid condensation errors. It is technically demanding to heat the PT correctly, and this increases the complexity of the equipment. We have studied whether a simpler method can eradicate condensation errors and preserve thermal stability of the PT.

We tested the accuracy of a PT by recording the discharge of $1,000 \mathrm{ml}$ of air through the PT before and after a subject had blown through it, thus causing both condensation within the PT and a rise in its temperature. We then determined whether the thermal and condensation errors could be avoided by placing the PT, between blows, on a fan that was blowing air at a constant $1.65 l \cdot \mathrm{s}^{-1}$.

With ambient temperature at $20^{\circ} \mathrm{C}$, a single blow through the PT was found to cause a subsequent $4 \%$ over-reading in volume, due to condensation and temperature changes in the PT. After five consecutive blows the error was 7\%. Placing the PT on the fan for $15 \mathrm{~s}$ after a single blow abolished these errors, whereas a wait of $15 \mathrm{~s}$ did not. At an ambient temperature of $14^{\circ} \mathrm{C}$ there was a $5 \%$ over-reading of volume after a single blow, and an over-reading of $9 \%$ after five blows. At an ambient temperature of $26^{\circ} \mathrm{C}$ these errors were 3 and $5 \%$, respectively. All of these errors were abolished by placing the PT on the fan for $15 \mathrm{~s}$ and $30 \mathrm{~s}$, respectively. These errors were significantly greater for a Fleisch as compared to a mesh screen type of pneumotachograph.

Placing a pneumotachograph, in between blows, in the flow stream of a fan blowing ambient air for $15 \mathrm{~s}$ minimizes errors due to condensation effects and temperature change in the pneumotachograph head.

Eur Respir J., 1994, 7, 198-201.
*Dept of Medicine, University of Birmingham, Good Hope Hospital, Sutton Coldfield, West Midlands, UK. **Institute of Environmental \& Occupational Medicine, Aarhus University, Universitetsparken, Bygning 180, Aarhus, Denmark.

Correspondence: M.R. Miller

Dept of Medicine

Good Hope Hospital

Rectory Road

Sutton Coldfield

West Midlands B75 7RR

UK

Keywords: Lung function pneumotachography temperature

Received: April 131993

Accepted after revision August 181993
Pneumotachographs (PTs) are widely used in lung function laboratories for recording maximal forced expiratory manoeuvres (MFEM). The stability and linearity of modern transducers, amplifiers, and analogue-to-digital converters have improved the performance of pneumotachographic recording in recent years. However, PTs are susceptible to: 1) changes in temperature, which alter correction factors and the prevailing gas viscosity; 2) changes in viscous resistance to gas flow as a consequence of condensation in the PT head; and 3) changes in the gas constituents.

The problems of temperature and condensation effects have in the past been addressed by heating the PT. There has been little guidance in the literature on how this heating should be performed or monitored, and there are many commercially available PTs that are not heated. One publication [1] has suggested that optimal conditions for recording MFEM with a PT are obtained by controlling the PT head to a temperature of $30^{\circ} \mathrm{C}$, using a thermocouple placed in a peripheral capillary of the PT head to give feed back control to the heating element. Such heating arrangements add to the technical complexity of using a PT, and would be difficult to achieve in a truly portable device. Furthermore, to heat a PT in a suboptimal way may lead to greater errors than would be obtained by not heating the PT at all [1].

We have undertaken experiments to determine the magnitude of the error from thermal and condensation effects when using an unheated PT, and we have determined whether placing the PT on a fan between blows can minimize these errors.

\section{Method}

We have studied a widely-used and commercially available unheated pneumotachograph (Vitalograph, Buckingham, UK), together with its $200 \mathrm{~mm}$ long plastic 
upstream assembly, which accepts standard $28 \mathrm{~mm}$ internal diameter cardboard mouthpieces, and have compared this to a mesh screen type of PT (type F300L, Mercury Electronics Ltd, Glasgow, Scotland). The pressure drop across the PTs was measured by a differential capacitance transducer (FC040, Furness Controls, Bexley, UK) the signal of which was sampled every $4 \mathrm{~ms}(250 \mathrm{~Hz})$ via a 12 bit analogue-to-digital converter and then stored in a computer. Flow was numerically integrated with respect to time, to give volume. The PTs were calibrated using a $1 l$ syringe, discharging ambient air through the PT with a peak flow of about $3 l \cdot \mathrm{s}^{-1}$. The integrated volume in the computer was then equated to the known discharged volume to derive a calibration factor.

The effect of temperature and condensation was determined by repeating the discharge of $1 l$ of ambient air from the syringe, as for the calibration procedure, but under different test conditions as summarized in figure 1. The recorded discharged volume was determined using the baseline calibration factor, and any variance from the expected $1 l$ indicated an effect due to either condensation within the PT head or a change in its temperature. The effect of placing each PT head in the outlet flow stream of a small fan producing a flow of $1.65 l \cdot \mathrm{s}^{-1}$ through the PT was then determined, to see if this prevented these temperature and condensation effects. Experiments were carried out in a climatically controlled room-sized chamber, at two selected temperatures on consecutive days, and further studies were at the uncontrolled ambient temperature. In between each experiment the PT was allowed to return to ambient conditions. One series of experiments was conducted using a $3 l$ syringe to determine if the magnitude of the errors changed.

The following basic protocol (shown schematically in figure 1) was followed. The PT system was calibrated by five discharges of $1 l$ of ambient air. A subject who had a forced vital capacity (FVC) $5.5 l$, peak expiratory

Step 1

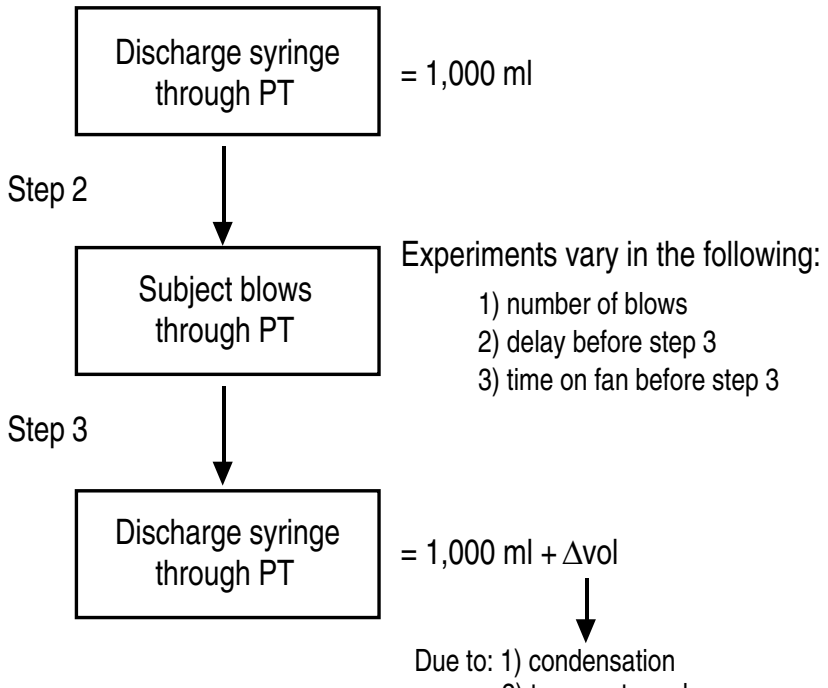

2) temperature change

Fig. 1. - Schematic representation of the experimental protocol. PT: pneumotachograph. flow (PEF) $10 l \cdot \mathrm{s}^{-1}$, forced expiratory time $5 \mathrm{~s}$ performed one or five MFEM through the PT and then $1 l$ of ambient air was again discharged through the PT either straight away, after a timed delay, or after a timed period on the fan. The apparent volume registered using the original calibration factor was recorded. All the results are the mean \pm SD for five repetitions of each experiment.

We also tested both pneumotachographs using a computercontrolled pump [2,3], which delivered American Thoracic Society (ATS) waveform PW24 [4] scaled to give known $\mathrm{FVC}$, forced expiratory volume in one second $\left(\mathrm{FEV}_{1}\right)$ and PEF repeatedly to the devices, before and after five blows were delivered through the PT. The scaled waveforms, No. 4 and No. 6, were chosen so that their respective PEF (200 and $300 l \cdot \mathrm{min}^{-1}$, approximately) were within the limits of linearity for both pneumotachographs.

Statistical analysis was performed using Minitab Version 7 on a microcomputer, with comparisons between means being tested by a two sample Student's t-test, unless otherwise stated. A probability of less than 5\% was accepted as significant.

\section{Results}

With the climate chamber set to an ambient temperature of $20^{\circ} \mathrm{C}$ (relative humidity $25 \%$, barometric pressure $102.3 \mathrm{kPa}) 1,000 \mathrm{ml}$ was discharged through the PT immediately after the subject's blow, and then again after a $15 \mathrm{~s}$ wait. The baseline recorded volume (mean \pm SD) was $1,000 \pm 2.1 \mathrm{ml}$, which rose significantly to $1,042 \pm 2.0$ $\mathrm{ml}(\mathrm{p}<0.0001)$ immediately post-blow, and fell slightly to $1,034 \pm 4.2 \mathrm{ml}$ following a further $15 \mathrm{~s}$ wait. This experiment was repeated with the $15 \mathrm{~s}$ wait following immediately after the subject's blow, that is before any testing was done, and the recorded volume was still significantly higher at $1,037 \pm 2.8 \mathrm{ml}$ after the wait $(\mathrm{p}<0.0001)$ when compared to the baseline of $1,000 \pm 1.5 \mathrm{ml}$. When this wait was extended to $60 \mathrm{~s}$ the recorded volume of $1,034 \pm 5.3 \mathrm{ml}$ was not significantly different from the recorded volume after a wait of $15 \mathrm{~s}$.

The experiment was then repeated with a subject blowing through the PT, followed immediately by the $1,000 \mathrm{ml}$ being discharged through the PT, then the PT was placed for $15 \mathrm{~s}$ on the fan, followed by a further $1,000 \mathrm{ml}$ being discharged through the PT. The baseline volume was $1,000 \pm 2.4 \mathrm{ml}$, rising to $1,040 \pm 3.1$ after the blow, and was subsequently $997 \pm 3.3 \mathrm{ml}$ after the $15 \mathrm{~s}$ on the fan. Although this volume recorded after the time on the fan was slightly below $1,000 \mathrm{ml}$, it was not significantly different from the baseline volume $(\mathrm{p}=0.2)$. When this experiment was repeated with five consecutive blows at $30 \mathrm{~s}$ intervals, before discharging the $1,000 \mathrm{ml}$ through the PT, the recorded volume rose from a baseline of $1,000 \pm 2.8 \mathrm{ml}$ to $1,073 \pm 3.1$, and $15 \mathrm{~s}$ on the fan reduced it to $998 \pm 1.0 \mathrm{ml}$.

These experiments were repeated with the climate chamber set to a temperature of $14^{\circ} \mathrm{C}$ (relative humidity $27 \%$, barometric pressure $102.7 \mathrm{kPa}$ ). When $1,000 \mathrm{ml}$ was discharged through the PT immediately after the subject's blow, the volume rose from a baseline of 
Table 1. - Results of FVC, FEV and PEF from the two ATS PW24 profiles recorded by the mesh screen pneumotachograph before and after five blows

\begin{tabular}{lcccccc}
\hline & $\begin{array}{c}\text { Start PW24 } \\
\text { No. 4 }\end{array}$ & $\begin{array}{c}\text { After 5 } \\
\text { blows }\end{array}$ & $\% \Delta$ & $\begin{array}{c}\text { Start PW24 } \\
\text { No. 6 }\end{array}$ & $\begin{array}{c}\text { After 5 } \\
\text { blows }\end{array}$ & $\% \Delta$ \\
\hline FVC ml & $2013 \pm 1$ & $2040 \pm 3$ & 1.34 & $2861 \pm 2$ & $2895 \pm 3$ & 1.19 \\
FEV $_{1} \mathrm{ml}$ & $1509 \pm 1$ & $1531 \pm 2$ & 1.46 & $2163 \pm 2$ & $2183 \pm 3$ & 0.92 \\
PEF $l \cdot \mathrm{min}^{-1}$ & $217 \pm 0.5$ & $220 \pm 0.7$ & 1.38 & $303 \pm 0.1$ & $307 \pm 0.1$ & 1.32 \\
\hline
\end{tabular}

Data are presented \pm SD. FVC: forced vital capacity; $\mathrm{FEV}_{1}$ : forced expiratory volume in one second; PEF: peak expiratory flow; ATS: American Thoracic Society.

Table 2. - Results of FVC, FEV and PEF from the two ATS PW24 profiles recorded by the Fleisch pneumotachograph before and after five blows

\begin{tabular}{lcccccc}
\hline & $\begin{array}{c}\text { Start PW24 } \\
\text { No. 4 }\end{array}$ & $\begin{array}{c}\text { After 5 } \\
\text { blows }\end{array}$ & $\% \Delta$ & $\begin{array}{c}\text { Start PW24 } \\
\text { No. 6 }\end{array}$ & $\begin{array}{c}\text { After 5 } \\
\text { blows }\end{array}$ & $\% \Delta$ \\
\hline FVC $\mathrm{ml}$ & $2001 \pm 1$ & $2130 \pm 2$ & 6.45 & $3010 \pm 2$ & $3151 \pm 4$ & 4.68 \\
FEV $_{1} \mathrm{ml}$ & $1495 \pm 1$ & $1594 \pm 1$ & 6.62 & $2239 \pm 1$ & $2351 \pm 3$ & 5.00 \\
PEF $^{l} \cdot \mathrm{min}^{-1}$ & $209 \pm 0.3$ & $222 \pm 0.9$ & 6.22 & $305 \pm 1.2$ & $322 \pm 1.8$ & 5.57 \\
\hline
\end{tabular}

Data are presented as \pm SD. For abbreviations see legend to table 1 .

$1,000 \pm 2.1 \mathrm{ml}$ to $1,048 \pm 2.9 \mathrm{ml}$, and $15 \mathrm{~s}$ on the fan reduced this to $1,001 \pm 2.9 \mathrm{ml}$, which was not significantly different from the baseline reading. If the subject blew five times consecutively through the PT with $30 \mathrm{~s}$ between each blow, the recorded volume rose from $1,000 \pm 2.0 \mathrm{ml}$ to $1,094 \pm 2.9 \mathrm{ml}$, and $30 \mathrm{~s}$ on the fan corrected this to $1,004 \pm 1.7 \mathrm{ml}$, which was not significantly different from the baseline value.

With the ambient temperature uncontrolled at $26^{\circ} \mathrm{C}$ (relative humidity $25 \%$, barometric pressure $99.1 \mathrm{kPa}$ ) a single blow through the PT raised the recorded volume from $1,000 \pm 1.6$ to $1,032 \pm 2.7 \mathrm{ml}$, and after five blows at $30 \mathrm{~s}$ intervals this was $1,049 \pm 5.5 \mathrm{ml}$. When the PT was placed on a fan for $15 \mathrm{~s}$, after a single blow the reading of the PT was $1,001 \pm 2.3$, and this was not significantly different from baseline reading $(\mathrm{p}=0.13)$. After five blows followed by $30 \mathrm{~s}$ on the fan, the reading was $1,003 \pm 2.8$, which was not significantly different from baseline $(\mathrm{p}=0.11)$. A $3,000 \mathrm{ml}$ calibrating syringe was then used, giving a baseline reading of $3,000 \pm 14.2 \mathrm{ml}$ rising to $3,056 \pm 10.0 \mathrm{ml}$ after a single blow, and $15 \mathrm{~s}$ on the fan reduced this to $2,995 \pm 7.7 \mathrm{ml}$. The error found using the $3,000 \mathrm{ml}$ syringe after a single blow of $1.9 \%$ was significantly smaller $(\mathrm{p}<0.005)$ than the $3.2 \%$ error found when using the $1,000 \mathrm{ml}$ syringe.

When the Fleisch PT was compared to the mesh screen PT at an ambient temperature of $23^{\circ} \mathrm{C}$ (relative humidity $26 \%$ and barometric pressure of $101.1 \mathrm{kPa}$ ) the effect of five blows was to raise the calibration volume from $1,000 \pm 1.0 \mathrm{ml}$ to $1,084 \pm 4.0$ for the Fleisch, and to $1,031 \pm 7.6$ for the mesh screen PT. The increase for the mesh screen PT was significantly less than that for the Fleisch $(\mathrm{p}<0.02$, Mann Whitney). A period of $30 \mathrm{~s}$ on the fan brought these volumes back to $1,002 \pm 3.2$ and $996 \pm 2.2 \mathrm{ml}$, respectively, which were not significantly different from the baseline values. The results from using two scaled versions of ATS profile 24 are presented in tables 1 and 2. For FVC, $\mathrm{FEV}_{1}$ and PEF there were significant changes with both PTs after five blows ( $<<0.02$, Mann Whitney). For the Fleisch there was on average a 5-6\% increase in each reading after five blows, which was significantly larger than the average $1 \%$ increase for the mesh screen type of PT $(\mathrm{p}<0.02$, Mann Whitney).

\section{Discussion}

We have shown that an unheated pneumotacograph is affected by temperature and condensation effects, such that with a Fleisch type PT a second blow may be overestimated by $3-5 \%$. After five blows this overestimate rises to 5-9\%. As expected these errors were dependent on the ambient temperature. The results from the mesh screen type of PT showed that this was significantly less affected, with only a 3\% overestimate after five blows. Because this mesh screen type of PT has little heat capacity in its head, it is likely that these smaller errors were mainly due to condensation, rather than differences in heat transfer between the PT and the gas passing through. By placing either PT on a fan for just $15 \mathrm{~s}$ between blows, all these errors were completely removed.

We chose to use a $1,000 \mathrm{ml}$ calibrating syringe to detect these changes, in order to minimize the removal of heat and condensation from the PT due to the passage of a volume of gas through the PT. When the $3,000 \mathrm{ml}$ syringe was used, the error of $1.9 \%$ at $26^{\circ} \mathrm{C}$ after a single blow was significantly smaller than the $3.2 \%$ error found with the $1,000 \mathrm{ml}$ syringe, indicating that heat and condensation was being removed by the extra gas. Our estimates of the true errors will, therefore, be slightly low because even the passage of $1,000 \mathrm{ml}$ of gas through the PT will remove heat and condensation from within the PT. Another possible confounding factor is the fact that after a single blow the PT will be filled with warm gas, filling the PT's dead space $(50 \mathrm{ml})$. This gas contributed to the volume measured when a subsequent 
$1,000 \mathrm{ml}$ of ambient air was discharged through the PT, and being at a higher temperature would increase the recorded result. The experiments with a prolonged delay after a single blow before testing the PT allowed this dead space gas in the PT to cool, but even a delay of $60 \mathrm{~s}$ did not substantially reduce the error. Any dead space gas effect would be proportionally reduced when the $3,000 \mathrm{ml}$ syringe was used, and yet a significant error was still obtained. These results suggest that our estimates of the errors due to the combined effect of condensation and temperature will be close to the true error, and are not due to problems with the recording method.

There are many unheated PTs in clinical use, and using a fan in the way that we describe can minimize the condensation and temperature errors. An alternative method of avoiding these effects is to heat the PT head. Very little is known about how best to heat a pneumotachograph to prevent thermal and condensation errors, and the mesh screen type of pneumotachograph does not lend itself to being heated. Turney and Blumenfeld [5] presented data using dry gas passing through a PT under steady-state conditions. They used an uncontrolled $6 \mathrm{v}$ direct current (DC) applied to the heating coils of a Fleisch PT. In our hands, this produces a PT temperature in excess of $50^{\circ} \mathrm{C}$, which is an inappropriate temperature to work with. Furthermore, steady-state temperature conditions are not achieved during a MFEM through a heated PT [1]. A cumbersome arrangement of inspiratory and expiratory heat exchangers has been tried [6] for tidal breathing manoeuvres, and the measured change in temperature of $14.6^{\circ} \mathrm{C}$ across the unheated PT was reduced to less than $1^{\circ} \mathrm{C}[6]$. Our fan method is simple and suitable for single-breath manoeuvres but not for continuous breath-by-breath measurements.

Ideally the expired gas and PT head temperature should be constant during the manoeuvre, and PT calibration should be with gas under identical circumstances. With heated or unheated PTs these conditions are hard to meet. A previous report on the best method for heating a PT [1] found that, with the upstream geometry they used, a PT temperature of $30^{\circ} \mathrm{C}$ was optimal for recording expiratory manoeuvres. Even with their sophisticated temperature controller the temperature of the PT head did not stay constant. Heating the PT to a higher temperature led to marked cooling of the PT head, and this might cause a greater error than the rise in temperature during a blow through an unheated PT.

We conclude that when using an unheated pneumotachograph to record maximal forced expiratory manoeuvres, the pneumotachograph should be placed between blows in the airstream of a fan, in order to maintain the thermal stability of the pneumotachograph and to avoid the accumulation of condensation.

\section{References}

1. Miller MR, Pincock AC. - Linearity and temperature control of the Fleisch pneumotachograph. J Appl Physiol 1986; 60: 710-715.

2. Miller MR, Dickinson SA, Hitchings DJ. - The accuracy of portable peak flow meters. Thorax 1992; 47: 904-909.

3. Pincock AC, Miller MR. - The effect of temperature on recording spirograms. Am Rev Respir Dis 1983; 128: 894-898.

4. Standardization of Spirometry. - 1987 update. Am Rev Respir Dis 1987; 136: 1285-1298.

5. Turney SZ, Blumenfeld W. - Heated Fleisch pneumotachometer: a calibration procedure. J Appl Physiol 1973; 34: 117-121.

6. Smith WDA. - The measurement of uptake of nitrous oxide by pneumotachography. I. Apparatus, methods and accuracy. Brit J Anaesth 1964; 36: 363-377. 